\title{
Chemical Profile, In Vitro Antioxidant, Pancreatic Lipase, and Alpha-Amylase Inhibition Assays of the Aqueous Extract of Elettaria cardamomum L. Fruits
}

\author{
Hanan M. Al-Yousef ${ }^{D},{ }^{1}$ Ali S. Alqahtani ${ }^{(D)},{ }^{1}$ Wafaa H. B. Hassan ${ }^{D},{ }^{2}$ Afraa Alzoubi, \\ and Sahar Abdelaziz ${ }_{(\mathbb{D})}^{2}$ \\ ${ }^{1}$ Department of Pharmacognosy, College of Pharmacy, King Saud University, P.O. Box 2457, Riyadh 11451, Saudi Arabia \\ ${ }^{2}$ Department of Pharmacognosy, Faculty of Pharmacy, Zagazig University, Zagazig 44519, Egypt \\ Correspondence should be addressed to Sahar Abdelaziz; sah_abdelaziz@zu.edu.eg
}

Received 24 February 2021; Revised 14 May 2021; Accepted 20 May 2021; Published 29 May 2021

Academic Editor: Jean-Marie Nedelec

Copyright (C) 2021 Hanan M. Al-Yousef et al. This is an open access article distributed under the Creative Commons Attribution License, which permits unrestricted use, distribution, and reproduction in any medium, provided the original work is properly cited.

\begin{abstract}
Phytochemical and pharmacological investigations of Elettaria cardamomum L. were mostly focused on its essential oil and organic crude extracts with little attention on its aqueous extracts. Therefore, the current study aimed to investigate the phytochemical profile, in vitro antiobesity, and antidiabetic activities of the aqueous extract of Elettaria cardamomum L. family Zingiberaceae. UPLC-ESI-MS/MS analysis is used for the aqueous extract characterization in both ionization modes. The analysis revealed the tentative identification of forty-seven compounds based on their MS/MS fragmentation pattern and comparison with the reported data. The identified compounds include eight flavones, thirteen phenolic and nonphenolic acids, one coumarin, and nineteen anthocyanins. Moreover, the in vitro antiobesity and antidiabetic activities were also studied. The results showed that E. cardamomum L. aqueous extract inhibits pancreatic lipase and $\alpha$-amylase enzyme in a concentration-dependent manner, as $1 \mathrm{mg} / \mathrm{mL}$ extract was able to inhibit pancreatic lipase and $\alpha$-amylase by $62.25 \% \pm 0.58\left(\mathrm{IC}_{50}=288.75 \pm 1.3 \mu \mathrm{g} / \mathrm{mL}\right)$ and $70.42 \% \pm 1.5$ $\left(\mathrm{IC}_{50}=220.5 \pm 1.3 \mu \mathrm{g} / \mathrm{mL}\right)$, respectively. Conclusively, the current study indicated that the investigated biological activities of Elettaria cardamomum aqueous extract were attributed to the existence of biologically active metabolites such as flavones, phenolic and nonphenolic acids, coumarins, and anthocyanins. Moreover, it proposed that the aqueous cardamom extract can be used as a natural potential source in different pharmaceutical preparations to protect against variable chronic disorders, especially obesity and diabetes. Deeper in vivo investigations, isolation, purification, and structural elucidation of the major active metabolites from cardamom are recommended.
\end{abstract}

\section{Introduction}

Plants and their secondary metabolites have played a crucial and important role in the human's life particularly those which are used in traditional medicine or as food due to their healing and nutritional properties[1]. Spices are often used as food additives and considered a promising source for finding newer digestive enzyme inhibitors that do not have the same side effects as synthetic ones $[2,3]$.

Spices are well known to improve gastric function by increasing salivary flow and gastric juice secretions and help in digestion [3]. Elettaria cardamomum L. is a member of the family Zingiberaceae. It is known as "Queen of Spices" and considered as the second essential "national spice" of India [4]. Traditionally, cardamom is used to treat different disorders, such as gum infections, asthma, cataracts, and cardiac, digestive, and kidney diseases. It also has antidiabetic, anti-inflammatory, antioxidant, and anticarcinogenic effects $[5,6]$.

Most of the previous biological investigations focused on cardamom volatile oil [7] which has valuable constituents such as terpene, esters, and flavonoids. The major constituents of cardamom volatile oil are 1,8-cineole (36.3\%) and $\alpha$-terpinyl acetate (31.3\%). It was also reported that organic 
fractions of cardamom crude extracts contain many flavonoid constituents such as luteolin, quercetin, kaempferol, and pelargonidin $[5,8]$. However, nothing was reported about the nonvolatile constituents of the aqueous extract of cardamom or its biological activities. Therefore, the aim of the present study is to investigate the aqueous extract of cardamom fruits using UPLC-ESI-MS/MS and to evaluate its in vitro antiobesity and antidiabetic activities.

\section{Materials and Methods}

2.1. Preparation of Cardamom Aqueous Extracts. Green cardamom (obtained from Spices Board, Cochin, Kerala, India) was used for this study. The plant was verified by Prof Dr. Husain Abdel Basset, professor of Taxonomy, Faculty of Science, Zagazig University, Egypt. A voucher specimen (\#EC-519) was prepared and deposited at the herbarium in the Department of Pharmacognosy, Faculty of Pharmacy, Zagazig University. Eighty grams of the fruits and seeds of E. cardamomum were ground, and the powder was mixed with $800 \mathrm{~mL}$ of distilled water and agitated at $150 \mathrm{rpm}$ at room temperature for $24 \mathrm{~h}$. The solution was then filtered using muslin cloth. The filtrate was paper filtered, then poured into a bottle, and placed in a freezer at $-70^{\circ} \mathrm{C}$. The frozen filtrate was subjected to lyophilization ( $\alpha$ 1-4 LDplus freeze dryer, Christ Co.) for $48 \mathrm{~h}$. A $1.350 \mathrm{~g}$ sample of the powder was collected for further analysis by UPLC-ESI-MS/ MS.

2.2. Chemicals. All chemicals and reagents used in the study were of analytical grade. $\alpha$-Amylase inhibitor, dinitro salicylic acid (DNS, a colour reagent), porcine pancreatic lipase, and $p$-nitrophenyl butyrate (NPB) were purchased from Sigma-Aldrich (St. Louis, MO, USA). All solvents used for extractions and quantification were purchased from SigmaAldrich (Al-Khobar, KSA), and HPLC-grade methanol for ESI-MS analyses was sourced from Gulf Scientific Corporation, Ltd. (Dubai, UAE). Formic acid and acetic acid were purchased from Sigma-Aldrich.

\subsection{UPLC-ESI-MS/MS Instrument and Separation Technique.}

The UPLC- ESI-MS/MS (ultra-performance liquid chromatography with electrospray ionization quadrupole linear ion trap tandem mass spectrometry) analysis performed on ESI-MS positive and negative ionization acquisition modes was carried out on a XEVO TQD triple quadruple instrument mass spectrometer. For the quantitative determination of the phytochemicals, a multiple-reaction monitoring (MRM) mode method was employed. E. cardamomum L. fruits aqueous extract was analyzed by UPLC to get the chromatographic profiles of the highly polar portions of the extracts, which contain polar compounds such as phenolic and flavonoid compounds. HPLC-grade methanol was used to dissolve the sample and filtered through $0.2 \mu \mathrm{m}$ membrane disc filter and resulting solution concentrations were in 0.2 to $0.5 \mathrm{mg} / \mathrm{mL}$ range, depending on each fraction. The UPLC system was a Waters Corporation, Milford, MA01757 U.S.A, mass spectrometer. The reverse-phase separations were performed (ACQUITY UPLC BEH C18 $1.7 \mu \mathrm{m}$, $2.1 \times 50 \mathrm{~mm}$ Column $)(50 \mathrm{~mm} \times 1.2 \mathrm{~mm}$ (inner diameter) and $1.7 \mu \mathrm{m}$ particle size) at $0.2 \mathrm{~mL} / \mathrm{min}$ flow rate. The gradient program previously reported in [9] was used for the analysis. The mobile phase consists of acidified water containing $0.1 \%$ formic acid (A) and acidified methanol containing $0.1 \%$ formic acid (B). The elution conditions were $0-2$ min $10 \%$ B isocratic; $2-5$ min, linear gradient B 10 to $30 \%$; 5-15 min, linear gradient from $30 \%$ to $70 \% \mathrm{~B}$; $15-22 \mathrm{~min}$, linear gradient from $70 \%$ to $90 \% \mathrm{~B} ; 22-25 \mathrm{~min}$, $90 \% \mathrm{~B}$ isocratic and lastly washing and reconditioning of column was carried out. To obtain more data, electrospray ionization (ESI) was performed in both negative and positive ion modes. The analysis parameters were carried out using negative ion mode as follows: source temperature $150^{\circ} \mathrm{C}$, cone voltage $30 \mathrm{eV}$, capillary voltage $3 \mathrm{kV}$, desolvation temperature $440^{\circ} \mathrm{C}$, cone gas flow $50 \mathrm{~L} / \mathrm{h}$, and desolvation gas flow $900 \mathrm{~L} / \mathrm{h}$. Mass spectra were detected in the ESI between $\mathrm{m} / z$ 100-1000 atomic mass units. The identification of the phytochemical constituents was done by their fragmentation patterns and ESI-QqQLIT-MS/MS spectra. Peaks and spectra were processed using the MassLynx 4.1 software and tentatively identified by comparing its retention time $\left(R_{t}\right)$, mass spectrum with reported data, and library search (such as FooDB (http://www.Foodb.ca)).

2.4. In Vitro Antidiabetic Assay Using $\alpha$-Amylase Inhibition Method. In this method, the solution of the enzyme was prepared by dissolving $\alpha$-amylase in $20 \mathrm{mM}$ phosphate buffer (6.9) at the concentration of $0.5 \mathrm{mg} / \mathrm{mL} .1 \mathrm{~mL}$ of the extract of various concentrations $(7.81-1000 \mu \mathrm{g} / \mathrm{mL})$ and $1 \mathrm{~mL}$ of enzyme solution were mixed and incubated at $25^{\circ} \mathrm{C}$ for $10 \mathrm{~min}$. After incubation time, $1 \mathrm{~mL}$ of starch $(0.5 \%)$ solution was added to the mixture and further incubated at $25^{\circ} \mathrm{C}$ for $10 \mathrm{~min}$. The reaction was stopped by the addition of $2 \mathrm{~mL}$ of dinitro salicylic acid (DNS, colour reagent), heating in a boiling water bath $(5 \mathrm{~min})$. After cooling, the absorbance was measured using a calorimeter at $565 \mathrm{~nm}$ (Spectrumlab S23A, Globe Medical, England). The percentage of inhibition was calculated using the given formula,

$$
\% \text { inhibition }=\left(1-\frac{A s}{A c}\right) \times 100,
$$

where $A s$ is the absorbance of tested extracts and $A c$ is the absorbance of control. Acarbose was used as a control [10]. The $\mathrm{IC}_{50}$ value is the concentration of $\alpha$-amylase inhibitor to inhibit $50 \%$ of its activity under the assay conditions. Nonlinear regression analysis of GraphPad Prism 5 software (GraphPad software, San Diego, California) was used to calculate $\mathrm{IC}_{50}$ from graphic plots of the dose response curve for each applied concentration. Each experiment was performed in triplicates, and all values are represented as means $\pm S D$.

\subsection{In Vitro Antiobesity Using Pancreatic Lipase Inhibitory} Assay. The lipase inhibition activity of E. cardamomum aqueous extract was determined by a method in [11]. In this method, the porcine pancreatic lipase activity was measured 
using $p$-nitrophenyl butyrate (NPB) as a substrate. Lipase solution $(100 \mu \mathrm{g} / \mathrm{mL})$ was prepared in a $0.1 \mathrm{mM}$ potassium phosphate buffer ( $\mathrm{pH}$ 6.0). Samples with different concentrations $(7.81-1000 \mu \mathrm{g} / \mathrm{mL})$ were preincubated with $100 \mu \mathrm{g} /$ $\mathrm{mL}$ of lipase for $10 \mathrm{~min}$ at $37^{\circ} \mathrm{C}$. The reaction was then started by adding $0.1 \mathrm{~mL} \mathrm{NPB}$ substrate. After incubation at $37^{\circ} \mathrm{C}$ for $15 \mathrm{~min}, \mathrm{p}$-nitrophenol amount released in the reaction was measured using Multiplate Reader (BioTek, Synergy HT, VT, USA). Orlistat was used with the same concentrations as a control. The results were expressed as percentage inhibition, which was calculated using the formula,

$$
\text { inhibitory activity }(\%)=\left(1-\frac{A s}{A c}\right) \times 100,
$$

where $(A c)$ is the absorbance of control and $(A s)$ is the absorbance in the presence of test substance. The concentration of pancreatic lipase inhibitor to inhibit $50 \%$ of its activity under the assay conditions is the $\mathrm{IC}_{50}$ value. Its $\mathrm{IC}_{50}$ was done from dose response curve graphic plots for each concentration by using nonlinear regression analysis of GraphPad Prism 5 software. Each experiment was performed in triplicates, and all values are represented as means \pm SD of triplicates.

\section{Results and Discussion}

3.1. Characterization of the Phytoconstituents of the Aqueous Extract of E. cardamomum L. Fruits. The polyphenolic constituents of E. cardamomum L. fruit aqueous extract was investigated for the first time using UPLC-ESI-MS/MS to identify its bioactive constituents related to their in vitro antiobesity and antidiabetic activities. Some of the identified compounds were previously reported in E. cardamomum.

Forty-seven compounds were tentatively identified by UPLC-ESI-MS/MS (negative and positive ionization modes) from the aqueous fraction of E. cardamomum (Figure 1). Table 1 shows the identified compounds with their retention time $\left(R_{t}\right)$, detected mass $(\mathrm{M} \pm \mathrm{H})$, and $\mathrm{MS} / \mathrm{MS}$ fragment ions. Chromatograms of some identified compounds are shown in Figure 2. The identified compounds include thirteen phenolic and nonphenolic acids $(2-7,9,11,16,18,25,37$, and 38), eight flavones $(1,14,15,17,20,22,24$, and 31$)$, one coumarin (8), and nineteen anthocyanins $(10,12,13,19,21$, $23,24,26,27,30,32,33,34,35,36,42,44$, and 45$)$ and two unknown compounds were also detected.

3.1.1. Phenolic and Nonphenolic Acids. In the aqueous extract, phenolic and nonphenolic acids were identified based on mass measurement, $\mathrm{MS}^{2}$ fragmentation patterns, and previous studies. Chromatograms in Figure 1 show the presence of thirteen acidic compounds. Compounds 6, 7, 9, 11 , and $18\left(R_{t} 2.53,4.90,5.74,8.69\right.$, and 9.56) showed a common pseudomolecular ion peak at $m / z 353[\mathrm{M}-\mathrm{H}]$ and $\mathrm{MS}^{2}$ fragments at $\mathrm{m} / z 191,179,173$, and 135 from a chlorogenic acid isomer, neochlorogenic acid, cryptochlorogenic acid, and chlorogenic acid, respectively [19]. Compounds 2 to 5, with $\mathrm{MS}^{1}$ at $297[\mathrm{M}-\mathrm{H}], 191[\mathrm{M}-\mathrm{H}]$, $171[\mathrm{M}+\mathrm{H}]$, and $155[\mathrm{M}+\mathrm{H}]$, and $\mathrm{MS}^{2}$ base peak fragment ions at $m / z 161,111,125$, and 109 , respectively, were identified as protocatechuic hexoside [14, 15], citric acid [16], gallic acid [17], and protocatechuic acid [18], respectively. Compound 16 with $\mathrm{MS}^{1}$ at $\mathrm{m} / z 137[\mathrm{M}-\mathrm{H}]$ and $\mathrm{MS}^{2}$ base peak fragment ions at 107 [M-H-CHO] were tentatively identified as protocatechualdehyde. It is noteworthy that protocatechualdehyde has been previously identified in E. cardamomum [18]. Compounds 25, 37, 38, and 43 showed pseudomolecular ions at $\mathrm{m} / z 187[\mathrm{M}-\mathrm{H}]^{-}, 313[\mathrm{M}+\mathrm{H}]^{+}$, $225[\mathrm{M}+\mathrm{H}]^{+}$, and $153[\mathrm{M}+\mathrm{H}]^{+}$. They were tentatively identified as azelaic, caftaric, sinapic, and methyl salicylic acids, respectively, based on the $\mathrm{MS}^{2}$ data reported in Table 1 and $[27,34,35,38]$.

3.1.2. Flavone Compounds. Compound 1 showed a pseudomolecular ion peak at $m / z 641[\mathrm{M}+\mathrm{H}]^{+}$and a base peak fragment ion at $m / z 305$, representing a loss of $336 \mathrm{amu}$ (quinoyl hexoside moiety) [35], leaving dihydroquercetin as an aglycone [12]. It was thus concluded to be dihydroquercetin (taxifolin) quinoyl hexoside. Compounds 14 and 20 showed a common pseudomolecular ion peak at $\mathrm{m} / \mathrm{z}$ $447[\mathrm{M}-\mathrm{H}]$, and mass data showed the same fragment ion at $\mathrm{m} / \mathrm{z} 285$ [M-H-162], corresponding to the loss of hexose moiety. Based on these results, compounds 14 and 20 were concluded to be kaempferol-3-O-hexoside or luteolin-7-Ohexoside [13]. Compound 15 showed a pseudomolecular ion peak at $m / z 463[\mathrm{M}-\mathrm{H}]$ and a base peak fragment ion at $m / z$ 301 , a loss of $162 \mathrm{amu}$, which was identified as quercetin-3$O$-hexoside. Compounds 17 and 22 were identified as isorhamnetin-7-O-dihexoside and naringenin-7-O-hexoside from $\mathrm{MS}^{1}$ and $\mathrm{MS}^{2}$ data presented in Table 1 [26]. Compounds 29 and 31 showed pseudomolecular ion peaks at $\mathrm{m} / \mathrm{z}$ $489[\mathrm{M}-\mathrm{H}]^{-}$and $475[\mathrm{M}+\mathrm{H}]^{+}$and base peak fragment ions at $m / z 285$ and 271, respectively, with neutral loss of $204 \mathrm{amu}$ (acetyl hexoside) moiety so that these compounds were tentatively identified as kaempferol-3-O-acetyl hexoside [23] and apigenin-7-O-acetyl hexoside $[30,31]$, respectively.

3.1.3. Anthocyanins. Nine compounds were identified as cyanidin derivatives based on their MS fragmentation, leading to cyanidin aglycone $(\mathrm{m} / \mathrm{z} 287)$ in the positive mode. Compound 10 was identified as cyanidin-3-O-acetyl rhamnoside with $\mathrm{m} / z 475$ and an $\mathrm{MS}^{2}$ fragment at 287, a loss of $188 \mathrm{amu}$ from acetyl rhamnoside [12]. Compounds 13 and 44 had a common protonated pseudomolecular ion peak at $\mathrm{m} / z 595$, with fragment ions at $\mathrm{m} / z 449$ and 287 and neutral losses of 146 and $162 \mathrm{amu}$ from coumaroyl and hexose moieties, respectively; they were identified as cyanidin-3-Ocoumaroyl hexoside [24]. Compound 24 had a $[\mathrm{M}+\mathrm{H}]^{+}$ion at $m / z 449$ and $\mathrm{MS}^{2}$ fragment ion at $\mathrm{m} / z$ 287, which is consistent with cyanidin-3-O-hexoside [22].

Compounds 26 and 28 had a common $[\mathrm{M}+\mathrm{H}]$ ion at $m /$ $z$ 535, which is consistent with cyanidin-3-O-malonyl hexoside [25]. Compound 34 had a $[\mathrm{M}+\mathrm{H}]^{-}$ion at $m / z 595$ and an $\mathrm{MS}^{2}$ fragment at $m / z 287$ (a loss of $308 \mathrm{amu}$ ), which is consistent with cyanidin-3-O-rutinoside [28]. Peak 35 had $[\mathrm{M}+\mathrm{H}]^{+}$at $m / z 593$, with main fragment ion at $m / z 287$ (loss of $306 \mathrm{amu}$ from cinnamoyl glucuronide) and was 


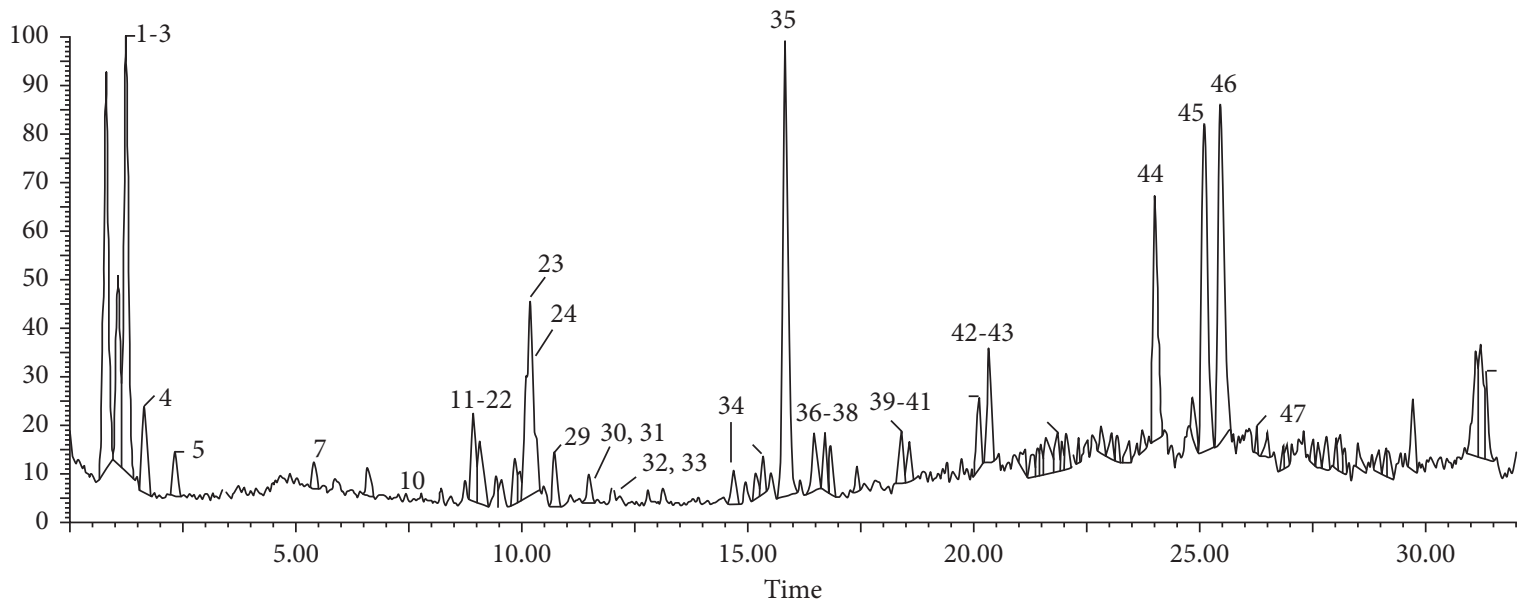

(a)

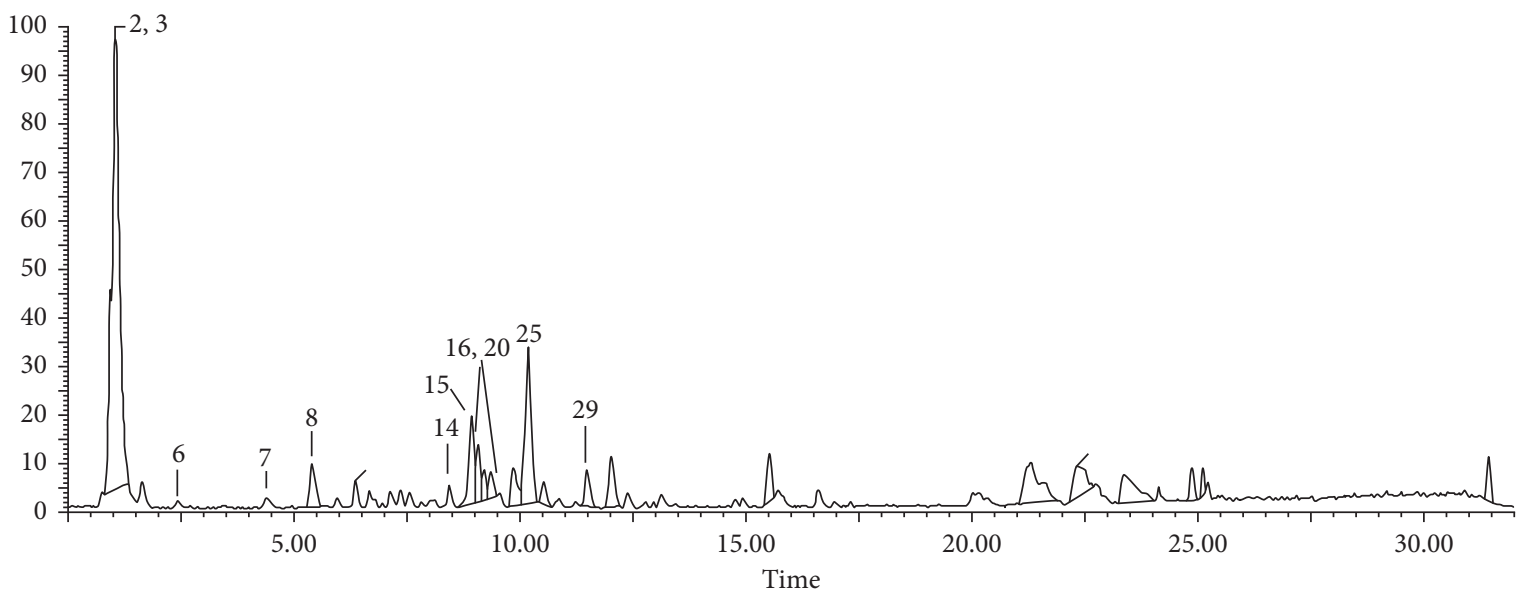

(b)

FIgURE 1: UPLS-ESI-MS chromatograms of E. cardamomum L. aqueous extract: (a) positive ion mode; (b) negative ion mode.

TABLE 1: Tentatively identified metabolites in the aqueous extract of E. cardamomum L. fruits (Card A) using UPLC-ESI-MS in negative and positive ionization modes.

\begin{tabular}{|c|c|c|c|c|c|c|}
\hline No. & Tentative assignment & $R_{t}(\min )$ & $\begin{array}{c}{[\mathrm{M}+\mathrm{H}]^{+}} \\
(m / z)\end{array}$ & $\begin{array}{c}{[\mathrm{M}-\mathrm{H}]^{-}} \\
(m / z)\end{array}$ & $\mathrm{MS}^{2}$ fragments $(\mathrm{m} / z)$ & Reference \\
\hline 1 & Taxifolin quinoyl hexoside & 0.96 & 641 & & $305(100 \%)$ & {$[12,13]$} \\
\hline 2 & Protocatechoyl glucoside & 0.95 & 299 & 297 & $161(100 \%)$ & {$[14,15]$} \\
\hline 3 & Citric acid & 1.29 & 193 & 191 & $111(100 \%)$ & {$[16]$} \\
\hline 4 & Gallic acid & 1.64 & 171 & & 125 & {$[17]$} \\
\hline 5 & Protocatechuic acid & 2.32 & 155 & & 109 & {$[18]$} \\
\hline 6 & Chlorogenic acid isomer & 2.53 & & 353 & $135(100 \%)$ & [19] \\
\hline 7 & Neochlorogenic acid & 4.90 & & 353 & $191(100 \%)$ & {$[19]$} \\
\hline 8 & Umbelliferone & 5.39 & 163 & & 135 (100\%), 107 & [20] \\
\hline 9 & Cryptochlorogenic acid & 5.74 & & 353 & $191,179,173$ (100\%), 135 & [19] \\
\hline 10 & Cyanidin-3-O-acetyl rhamnoside & 8.19 & 475 & & $287(100 \%)$ & {$[13]$} \\
\hline 11 & Chlorogenic acid isomer & 8.69 & 355 & 353 & $191(100 \%)$ & {$[19]$} \\
\hline 12 & Pelargonidin-3-O-feruloyl glucoside & 8.77 & 609 & & $271(100 \%)$ & {$[21]$} \\
\hline 13 & Cyanidin-3-O-coumaroyl glucoside & 8.87 & 595 & & $449,287(100 \%)$ & {$[22]$} \\
\hline 14 & Kaempferol or luteolin-3-O-glucoside & 8.93 & 449 & 447 & $285(100 \%)$ & [23] \\
\hline 15 & Quercetin-3-O-glucoside & 9.20 & 465 & 463 & 301 & [23] \\
\hline 16 & Protocatechualdehyde & 9.34 & 139 & 137 & $107(100 \%)$ & {$[18]$} \\
\hline 17 & Isorhamnetin-3-O-diglucoside & 9.38 & 641 & & 317 (100\%), 163 & {$[24]$} \\
\hline 18 & Chlorogenic acid isomer & 9.56 & 355 & & 193 & [19] \\
\hline 19 & Pelargonidin-3-O-glucoside & 9.83 & 433 & & $271(100 \%)$ & {$[25]$} \\
\hline
\end{tabular}


TABle 1: Continued.

\begin{tabular}{|c|c|c|c|c|c|c|}
\hline No. & Tentative assignment & $R_{t}(\min )$ & $\begin{array}{c}{[\mathrm{M}+\mathrm{H}]^{+}} \\
(m / z)\end{array}$ & $\begin{array}{c}{[\mathrm{M}-\mathrm{H}]^{-}} \\
(m / z)\end{array}$ & $\mathrm{MS}^{2}$ fragments $(\mathrm{m} / z)$ & Reference \\
\hline 20 & Kaempferol or luteolin-3-O-hexoside & 9.94 & 449 & 447 & $285(100 \%)$ & [23] \\
\hline 21 & Peonidin-3-O-hexoside & 9.96 & 463 & & $301(100 \%)$ & {$[25]$} \\
\hline 22 & Naringenin-7-O-hexoside & 9.98 & 435 & & $273(100 \%)$ & {$[26]$} \\
\hline 23 & Peonidin-3-O-coumaroyl glucoside & 10.16 & 609 & & $301(100 \%)$ & {$[25]$} \\
\hline 24 & Cyanidin-3-O-hexoside & 10.18 & 449 & & $287(100 \%)$ & {$[25]$} \\
\hline 25 & Azelaic acid & 10.52 & & 187 & $125(100 \%)$ & {$[27]$} \\
\hline 26 & Cyanidin-3-O-malonyl hexoside & 10.57 & 535 & & $287(100 \%)$ & {$[28]$} \\
\hline 27 & Delphinidin-3-O-feruloyl hexoside & 11.01 & 641 & & 303 & {$[21,29]$} \\
\hline 28 & Cyanidin-3-O-malonyl hexoside & 11.48 & 535 & & 449. $287(100 \%)$ & {$[28]$} \\
\hline 29 & $\begin{array}{c}\text { Kaempferol or luteolin-3-O-acetyl } \\
\text { hexoside }\end{array}$ & 11.48 & & 489 & 285 & {$[30]$} \\
\hline 30 & Cyanidin-3-O-acetyl hexoside & 12.10 & 491 & & $287(100 \%)$ & {$[25]$} \\
\hline 31 & Apigenin-7-O-acetyl hexoside & 12.20 & 475 & & $271(100 \%), 151$ & {$[31]$} \\
\hline 32 & Peonidin-3-O-coumaroyl hexoside & 12.81 & 609 & & $301(100 \%)$ & {$[25]$} \\
\hline 33 & Peonidin-3-O-feruloyl hexoside & 13.38 & 639 & & $301(100 \%)$ & {$[21,29]$} \\
\hline 34 & Cyanidin-3-O-rutinoside & 15.60 & 595 & & $287(100 \%)$ & {$[32]$} \\
\hline 35 & Cyanidin-3-O-cinnamoyl glucuronide & 15.82 & 593 & & $287(100 \%)$ & - \\
\hline 36 & Pelargonidin-3-O-diacetyl hexoside & 16.60 & 517 & & $271(100 \%)$ & {$[33]$} \\
\hline 37 & Caftaric acid & 16.80 & 313 & & 179 & {$[23,34]$} \\
\hline 38 & Sinapic acid & 16.95 & $225(100 \%)$ & & $209,179,151$ & {$[35]$} \\
\hline 39 & Maslinic acid & $\begin{array}{c}18.39[\mathrm{M}+\mathrm{H}- \\
\left.\mathrm{H}_{2} \mathrm{O}\right]\end{array}$ & 457 & & $\begin{array}{c}439,411,357,339,248,235,205 \\
179\end{array}$ & {$[34]$} \\
\hline 40 & Maslinic acid isomer & $\begin{array}{c}18.56[\mathrm{M}+\mathrm{H}- \\
\left.\mathrm{H}_{2} \mathrm{O}\right]\end{array}$ & 457 & & $357,339,248,235,205,179$ & {$[23]$} \\
\hline 41 & Vanillin & 18.86 & 153 & & $\begin{array}{c}138,125,121(100 \%), 107,89,81, \\
77\end{array}$ & {$[36]$} \\
\hline 42 & Malvidin-3-O-feruloyl glucoronide & 21.51 & 683 & & $331(100 \%)$ & {$[37]$} \\
\hline 43 & Methyl salicylic acid & 21.60 & 153 & & 121,91 & {$[38]$} \\
\hline 44 & Cyanidin-3-O-coumaroyl hexoside & 24.11 & 595 & & 449, 287 (100\%), & {$[22]$} \\
\hline 45 & Delphinidin-3-O-acetyl rhamnoside & 27.30 & 491 & & $303(100 \%)$ & [39] \\
\hline 45 & Unknown & 25.46 & $\begin{array}{c}381[\mathrm{M}+\mathrm{H}- \\
\left.\mathrm{H}_{2} \mathrm{O}\right]\end{array}$ & & 335,267 & - \\
\hline 46 & Catechin derivative & 25.50 & 595 & & $291(100 \%)$ & - \\
\hline 47 & Delphinidin-3-O-acetyl rhamnoside & 27.30 & 491 & & $303(100 \%)$ & [39] \\
\hline
\end{tabular}

tentatively identified as cyanidin-3-O-cinnamoyl glucuronide. Compound 30 had $[\mathrm{M}+\mathrm{H}]^{+}$at $m / z 491$ with main fragment ion at $\mathrm{m} / \mathrm{z} 287$ (loss of $204 \mathrm{amu}$ from acetyl hexose). It was tentatively identified as cyanidin-3-O-acetyl hexoside [22]. Four compounds were identified as peonidin derivatives based on their MS fragmentation leading to peonidin aglycone $(\mathrm{m} / z$ 301) in the positive mode. Compounds $21,23,32$, and 33 were identified as peonidin-3-Ohexoside, peonidin-3-O-coumaroyl hexoside, peonidin-3-Ocoumaroyl hexoside, and peonidin-3-O-feruloyl hexoside, respectively [29, 32].

Compounds 12, 19, and 36 were also identified as pelargonidin-3-O-feruloyl-hexoside [29], pelargonidin-3-Ohexoside [22], and pelargonidin-3-O-diacetyl hexoside [21], respectively, according to their mass spectra, with a distinctive fragment ion at $\mathrm{m} / z$ 271. Peaks 27 and 45 were identified as delphinidin-3-O-feruloyl-hexoside $[29,32]$ and delphinidin-3-O-acetyl rhamnoside, with $\mathrm{MS}^{1}$ at $\mathrm{m} / z 641$ and 491, respectively, and a common $\mathrm{MS}^{2}$ fragment at $\mathrm{m} / \mathrm{z}$ 303 , a loss of 338 amu from feruloyl hexoside moiety and of 188 amu from acetyl rhamnoside moiety, respectively [33]. Compound 42 was tentatively identified as malvidin derivative. It produced an $[\mathrm{M}+\mathrm{H}]^{+}$ion at $m / z 683$ and $\mathrm{MS}^{2}$ fragment ion at $m / z$ 331, neutral loss of $352 \mathrm{amu}$ (feruloyl glucuronide) moiety. It was tentatively identified as malvidin-3-O-feruloyl glucuronide [39].

3.1.4. Coumarins. One coumarin was identified in the aqueous extract of E. cardamomumfruits. Compound 8 was identified as umbelliferon, with $m / z 163[\mathrm{M}+\mathrm{H}]^{+}$and an $\mathrm{MS}^{2}$ base peak fragment ion at $m / z 135$ [37].

3.2. Antiobesity Activity. Obesity which is recently known as "new world syndrome" results from the interaction of nutritional, environmental, and genetic factors $[1,40]$. It is one of the worldwide health problems as it is associated with various chronic disorders such as hypertension, type 2 diabetes, dyslipidaemia, osteoarthritis, and cardiovascular, diseases. Pancreatic lipase enzyme secreted by the pancreas is responsible for $50-70 \%$ digestion of fats into monoglyceride and free fatty acids. Orlistat is an antiobesity drug which inhibits the dietary triglycerides hydrolysis and consequently decreases the subsequent intestinal absorption of monoglycerides and free fatty acids (lipolysis products). Despite of being the only drug for long-term control of 

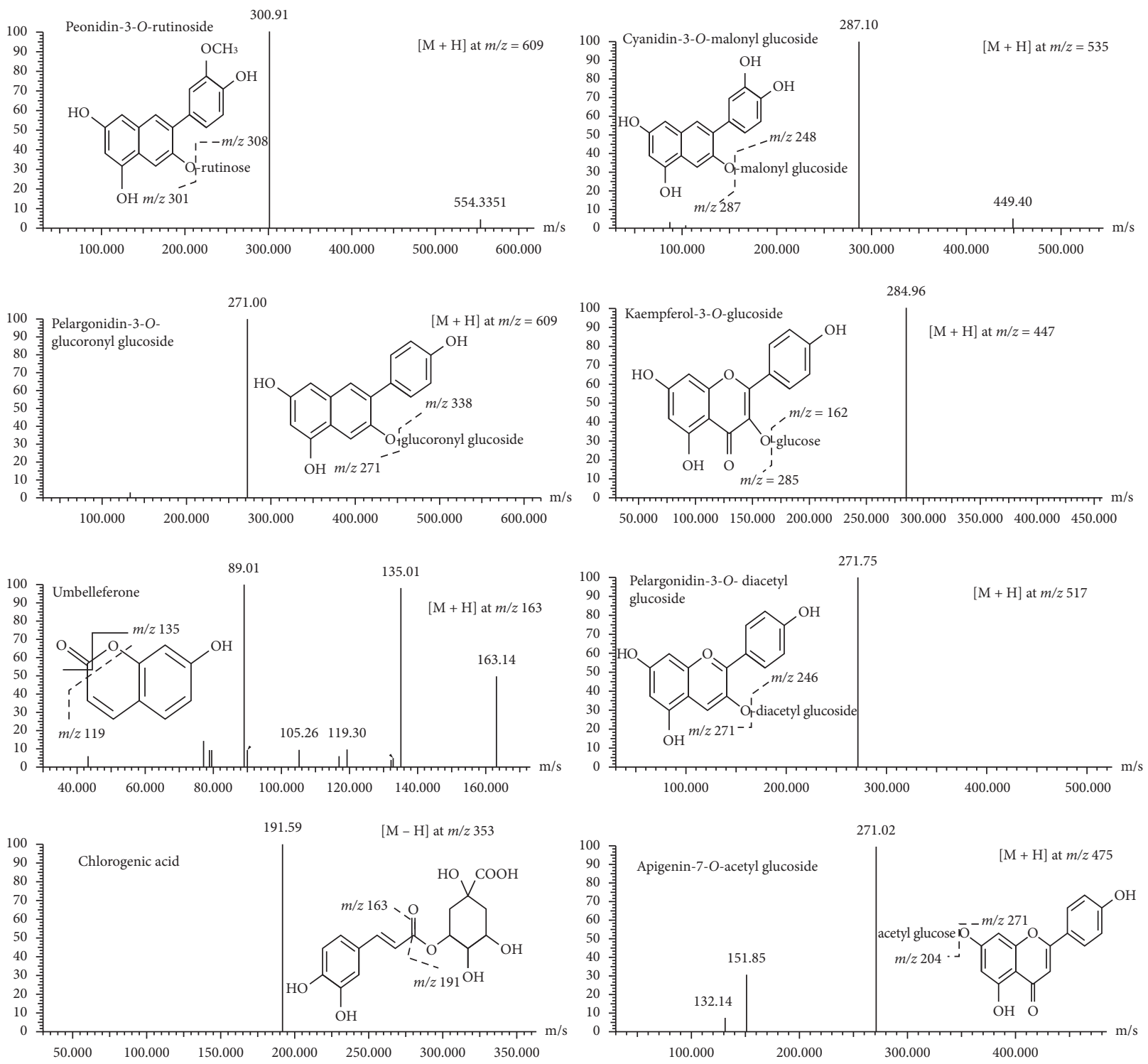

FIgURE 2: UPLC-ESI-MS/MS fragmentation of some identified compounds in E. cardamomum aqueous extract.

obesity, it has gastrointestinal side effects [40-42]. Therefore, natural products and plant-derived compounds have attracted the attention for the obesity management by developing safe and efficient antiobesity drugs [43].

The inhibitory activity of the aqueous extract on pancreatic lipase enzyme is shown in Table 2 and Figures 3(a) and $3(\mathrm{~b})$. The results demonstrated that E. cardamomum aqueous extract inhibits pancreatic lipase in a concentrationdependent manner; the inhibition \% ranged from $24.13 \% \pm 1.2$ to $70.42 \% \pm 1.5$ from the lowest to the highest concentration $(31.25-1000 \mu \mathrm{g} / \mathrm{ml})$. The $\mathrm{IC}_{50}$ of the extract was $(288.75 \pm 1.3 \mu \mathrm{g} / \mathrm{ml})$ while that of the orlistat standard was $\left(\mathrm{IC}_{50}=23.8 \pm 0.7 \mu \mathrm{g} / \mathrm{ml}\right)$. E. cardamomum aqueous extract in vitro inhibition of pancreatic lipase could be attributed to the presence of major biologically active polyphenolic metabolites such as anthocyanins and flavonoid compounds. Our findings are consistent with those previously published studies. Rahman et al. [36] reported
TABLE 2: Inhibition assay of pancreatic lipase activity of Elettaria cardamomum L. (Card A) at different concentrations.

\begin{tabular}{lcc}
\hline Concentration $(\mu \mathrm{g} / \mathrm{ml})$ & Card A & $\begin{array}{c}\text { Inhibition \% } \\
\text { Standard drug orlistat }\end{array}$ \\
\hline 7.81 & 0 & $29.31 \pm 1.4$ \\
15.63 & 0 & $45.25 \pm 3.1$ \\
31.25 & $24.13 \pm 1.2$ & $54.36 \pm 2.6$ \\
62.5 & $31.85 \pm 0.72$ & $60.35 \pm 2.1$ \\
125 & $42.87 \pm 0.63$ & $65.34 \pm 1.5$ \\
250 & $51.46 \pm 1.2$ & $80.12 \pm 0.58$ \\
500 & $61.98 \pm 2.1$ & $86.35 \pm 2.1$ \\
1000 & $70.42 \pm 1.5$ & $93.25 \pm 1.5$ \\
\hline
\end{tabular}

Data was represented as mean \pm SD.

that hepatic damage, dyslipidaemia, and oxidative stress can be prevented by cardamom powder supplementation in high carbohydrate and high fat diet fed rats. 


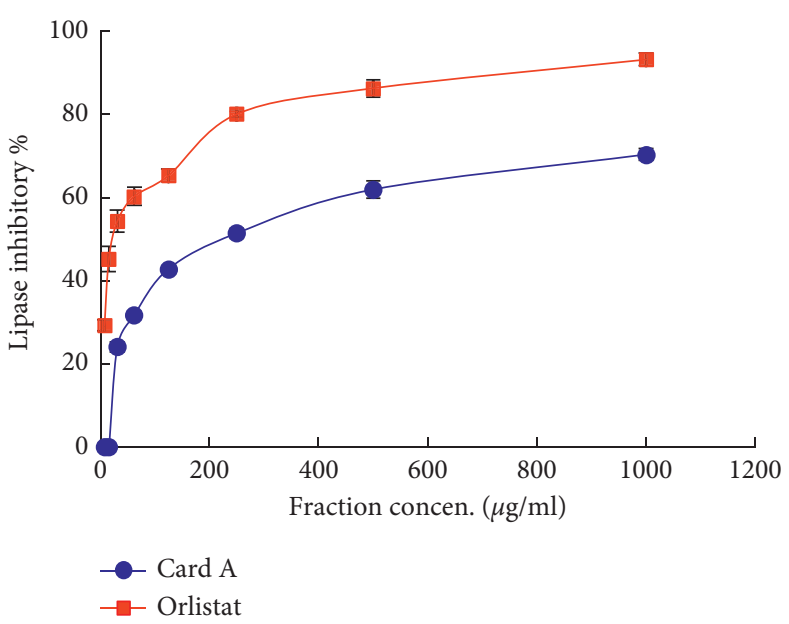

(a)

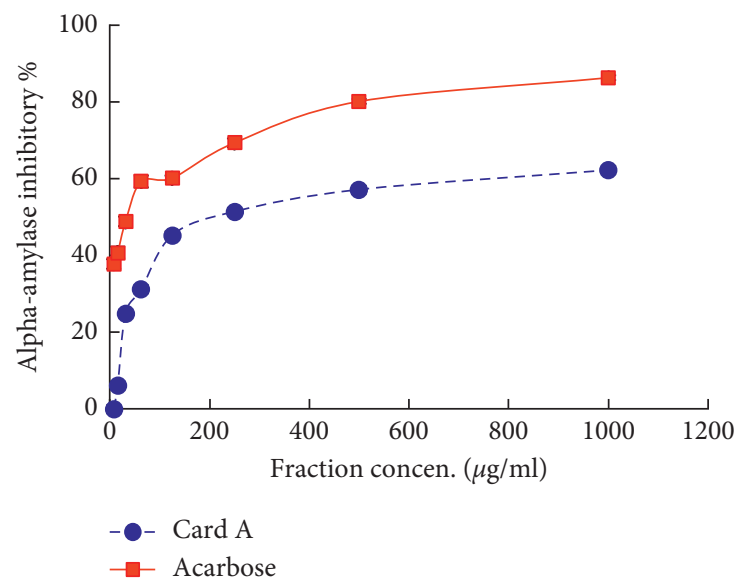

(c)

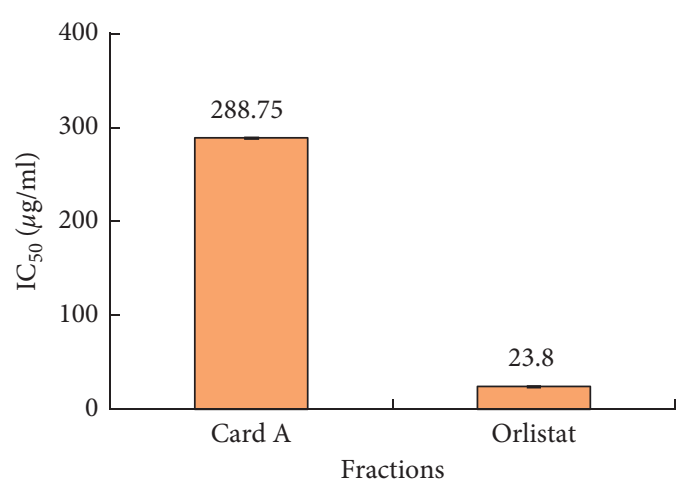

(b)

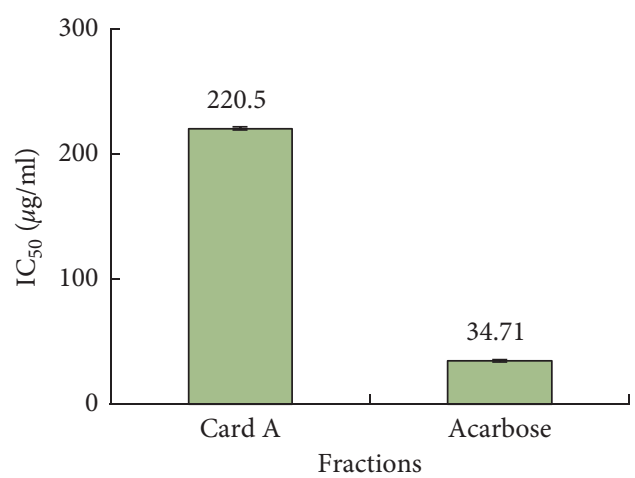

(d)

FIGURE 3: (a) In vitro pancreatic lipase inhibitory activity percentage of E. cardamomum L. aqueous extract (Card A) compared to orlistat standard. (b) $\mathrm{IC}_{50}$ of E. cardamomum L. aqueous extract (Card A) and orlistat. (c) In vitro $\alpha$-amylase inhibitory activity of E. cardamomum L. aqueous extract (Card A) compared to acarbose standard. (d) $\mathrm{IC}_{50}$ of E. cardamomum L. aqueous extract (Card A) and acarbose. Data are presented as averages \pm standard deviations from three experiments.

3.3. Antidiabetic Activity. Diabetes mellitus (DM) is a longterm metabolic disease characterized by elevated blood sugar levels. It may be attributed to a lack of insulin secretion, resistance to peripheral insulin's effects, or both. It affects around $10 \%$ of the population. Moreover, it is expected that diabetic patients may reach 230 million in 2025. DM is increasing all over the world, due to the prevalence of unhealthy habits, such as obesity, sedentarism, dietary patterns, smoking, or alcohol intake [44, 45].

Diabetes mellitus is usually accompanied by lipid, carbohydrate, and protein metabolic abnormalities. In patients with diabetes mellitus, chronic hyperglycemia, in combination with other metabolic disorders, can damage various organ systems, resulting in potentially fatal health complications, the most common of which are retinopathy, nephropathy, neuropathy, and cardiovascular disease [45]. Despite the availability of other therapeutic options, herbal remedies (medicinal plants or their extracts) are highly recommended for the treatment of diabetes since ancient times $[44,46]$. Alpha-amylase and $\alpha$-glucosidase are digestion enzymes of carbohydrates which can significantly decrease the postprandial elevation of blood glucose after a carbohydrate diet. So, inhibition of these enzymes is considered as essential strategy in blood glucose management [10].

In the present study, the in vitro $\alpha$-amylase inhibitory activity of E. cardamomumfruits aqueous extract was investigated using variable doses $(7.81-1000 \mu \mathrm{g} / \mathrm{mL})$. The extract showed a good inhibition of carbohydrate-hydrolyzing enzymes ( $\alpha$-amylase) in a dose-dependent manner, as shown in Table 3 and Figures 3(c) and 3(d). The inhibition \% ranged from $6.17 \pm 1.7$ to $62.25 \pm 0.58$ from the lowest to the highest concentration $(15.63-1,000 \mu \mathrm{g} / \mathrm{ml})$. However, the highest inhibition \% of acarbose standard was $40.75 \pm 1.5$ to $86.32 \pm 0.63$ from lowest to highest concentration, as shown in Table 3. The $\mathrm{IC}_{50}$ of the extract was $(220.5 \pm 1.3 \mu \mathrm{g} / \mathrm{ml})$ while that of the acarbose standard was $\left(\mathrm{IC}_{50}=34.71 \pm 0.7 \mu \mathrm{g} / \mathrm{ml}\right)$. The antidiabetic activity may be attributed to the presence of anthocyanins (cyanidin-3-O-cinnamoyl glucuronide, cyanidin-3-O-coumaroyl hexoside, cyanidin-3-O-hexoside, 
TABLE 3: Inhibition assay of $\alpha$-amylase activity of E. cardamomum L. (Card A) at different concentrations.

\begin{tabular}{lcc}
\hline Concentration $(\mu \mathrm{g} / \mathrm{ml})$ & Card A & $\begin{array}{c}\text { Inhibition \% } \\
\text { Standard drug acarbose }\end{array}$ \\
\hline 7.81 & 0 & $37.81 \pm 1.2$ \\
15.63 & $6.17 \pm 1.7$ & $40.75 \pm 1.5$ \\
31.25 & $24.93 \pm 1.2$ & $48.84 \pm 1.2$ \\
62.5 & $31.15 \pm 0.72$ & $59.31 \pm 1.5$ \\
125 & $45.28 \pm 1.5$ & $60.17 \pm 0.63$ \\
250 & $51.46 \pm 1.2$ & $69.37 \pm 1.2$ \\
500 & $57.19 \pm 2.1$ & $80.14 \pm 0.58$ \\
1000 & $62.25 \pm 0.58$ & $86.32 \pm 0.63$ \\
\hline
\end{tabular}

Data are represented as mean \pm SD.

peonidin-3-O-coumaroyl glucoside, and malvidin-3-O-feruloyl glucuronide) and flavonoids (taxifolin quinoyl hexoside and quercetin-3-O-hexoside).

Anthocyanin is considered one of the most important classes of polyphenols which play a key role in the treatment and prevention of type 2 diabetes mellitus [47]. It was reported that cyanidin, delphinidin, malvidin, and cyanidin-3$O$-glucoside are the most potent anthocyanins for alphaamylase inhibition. Moreover, cyanidin and its glucosides have been shown to inhibit carbohydrate-digestive enzymes by forming covalent and/or noncovalent bonds between their hydroxyl groups and the polar residues of the enzyme active sites [44, 45].

Recently, flavonoids' activity has been investigated even up to clinical studies for diabetes management in humans. The findings are compiled in several reviews [48-50]. Flavonoids have also been identified as $\alpha$-amylase inhibitors in other studies [51]. Additionally, flavonoids are considered as natural alternative in diabetes treatment as they can regulate insulin secretions through different mechanisms. For example, taxifolin-3-O-rhamnoside works in a mechanism like sulfonylureas by $\mathrm{K}_{\mathrm{ATP}}$ channel closure and cell surface $\mathrm{Ca}^{2+}$ channel signaling pathway opening [52].

\section{Conclusion}

In the present study, the aqueous extract of E. cardamomum fruits was investigated for the first time using UPLC-ESI/MS/ MS in both negative and positive ionization modes. The antidiabetic and antiobesity activities of the extract were also evaluated in vitro. The results revealed the tentative identification of forty-seven compounds including (anthocyanins, flavones, and phenolic and nonphenolic acids). E. cardamomum aqueous extract showed a good antidiabetic and antiobesity activities which may be related to the presence of major biologically active metabolites (cyanidin-3-O-coumaroyl hexoside, cyanidin-3-O-hexoside, azelaic acid, and taxifolin quinoyl hexoside) with reported antioxidant, antiobesity, and antidiabetic activities. Finally, future bioavailability and pharmacokinetic studies of E. cardamomum fruit are recommended to identify and isolate its active metabolites and expand its medical application.

\section{Data Availability}

The data used to support the findings of this study are included in the manuscript.

\section{Conflicts of Interest}

The authors declare that they have no conflicts of interest.

\section{Authors' Contributions}

All authors made considerable contributions to the manuscript. HA, AA, WH, AA, and SA designed the study. $\mathrm{WH}$, $\mathrm{HA}$, and SA performed the experiments. HA, AA, and SA interpreted the results. $\mathrm{AA}, \mathrm{WH}, \mathrm{HA}, \mathrm{AA}$, and SA wrote the manuscript. All authors revised the manuscript and confirmed it for publication.

\section{Acknowledgments}

The authors are thankful to the Researchers Supporting Project no. (RSP-2020/132), King Saud University, Riyadh, Saudi Arabia, for supporting the study.

\section{References}

[1] N. Jaradat, A. Zaid, F. Hussein, M. Zaqzouq, H. Aljammal, and O. Ayesh, "Anti-lipase potential of the organic and aqueous extracts of ten traditional edible and medicinal plants in Palestine; a comparison study with orlistat," Medicines, vol. 4, no. 4, p. 89, 2017.

[2] I. T. Fernando, K. I. Perera, S. B. P. Athauda, R. Sivakanesan, N. S. Kumar, and L. Jayasinghe, "Heat stability of the in vitro inhibitory effect of spices on lipase, amylase, and glucosidase enzymes," Food Science \& Nutrition, vol. 7, no. 2, pp. 425-432, 2019.

[3] K. Platel and K. Srinivasan, "Digestive stimulant action of spices: a myth or reality?" Indian Journal of Medical Research, vol. 119, no. 5, p. 167, 2004.

[4] P. Kaushik, P. Goyal, A. Chauhan, and G. Chauhan, "In vitro evaluation of antibacterial potential of dry FruitExtracts of Elettaria cardamomum maton (chhoti elaichi)," Iranian Journal of Pharmaceutical Research: IJPR, vol. 9, no. 3, pp. 287-92, 2010.

[5] M. Aghasi, S. Ghazi-Zahedi, F. Koohdani et al., "The effects of green cardamom supplementation on blood glucose, lipids profile, oxidative stress, sirtuin- 1 and irisin in type 2 diabetic patients: a study protocol for a randomized placebo-controlled clinical trial," BMC Complementary and Alternative Medicine, vol. 18, no. 1, pp. 1-6, 2018.

[6] N. M. Elguindy, G. A. Yacout, E. F. El Azab, and H. K. Maghraby, "Chemoprotective effect of Elettaria cardamomum against chemically induced hepatocellular carcinoma in rats by inhibiting NF- $\kappa \mathrm{B}$, oxidative stress, and activity of ornithine decarboxylase," South African Journal of Botany, vol. 105, pp. 251-258, 2016.

[7] K. Ashokkumar, M. Murugan, M. K. Dhanya, and T. D. Warkentin, "Botany, traditional uses, phytochemistry and biological activities of cardamom [Elettaria cardamomum (L.) Maton]-a critical review," Journal of Ethnopharmacology, vol. 246, Article ID 112244, 2020. 
[8] Y. Fatemeh, F. Siassi, A. Rahimi et al., "The effect of cardamom supplementation on serum lipids, glycemic indices and blood pressure in overweight and obese pre-diabetic women: a randomized controlled trial," Journal of Diabetes \& Metabolic Disorders, vol. 16, no. 1, p. 40, 2017.

[9] H. M. Al-Yousef, S. Abdelaziz, W. H. B. Hassan, and M. A. ElSayed, "Phytochemical and biological characterization of Tephrosia nubica boiss. Growing in Saudi Arabia," Arabian Journal of Chemistry, vol. 13, no. 12, pp. 9216-9230, 2020.

[10] M. B. Narkhede, P. V. Ajimire, A. E. Wagh, M. Mohan, and A. T. Shivashanmugam, "In vitro antidiabetic activity of Caesalpina digyna (R.) methanol root extract," Asian Journal of Plant Science and Research, vol. 1, no. 2, pp. 101-106, 2011.

[11] Y. S. Kim, Y. M. Lee, H. Kim et al., "Anti-obesity effect of Morus bombycis root extract: anti-lipase activity and lipolytic effect," Journal of Ethnopharmacology, vol. 130, no. 3, pp. 621-624, 2010.

[12] Z. Benayad, C. Gómez-Cordovés, and N. Es-Safi, "Characterization of flavonoid glycosides from fenugreek (trigonella foenum-graecum) crude seeds by HPLC-DAD-ESI/MS analysis," International Journal of Molecular Sciences, vol. 15, no. 11 , pp. 20668-20685, 2014.

[13] A. F. Faria, M. C. Marques, and A. Z. Mercadante, "Identification of bioactive compounds from jambolão (Syzygium cumini) and antioxidant capacity evaluation in different $\mathrm{pH}$ conditions," Food Chemistry, vol. 126, no. 4, pp. 1571-1578, 2011.

[14] Q. Ain, M. N. Naveed, A. S. Mumtaz, M. Farman, I. Ahmed, and N. Khalid, "Phytochemical analysis of Hibiscus caesius using high performance liquid chromatography coupled with mass spectrometry," Pakistan Journal of Pharmaceutical Sciences, vol. 28, no. 5, pp. 1625-9, 2015.

[15] B. Schuster, M. Winter, and K. Herrmann, "4-O- $\beta-\square$-Glucosides of hydroxybenzoic and hydroxycinnamic acids-their synthesis and determination in berry fruit and vegetable," Zeitschrift für Naturforschung C, vol. 41, no. 5-6, pp. 511-520, 1986.

[16] I. M. Abu-Reidah, D. Arráez-Román, M. Al-Nuri, I. Warad, and A. Segura-Carretero, "Untargeted metabolite profiling and phytochemical analysis of Micromeria fruticosa L. (Lamiaceae) leaves," Food Chemistry, vol. 279, pp. 128-143, 2019.

[17] R. M. Ibrahim, A. M. El-Halawany, D. O. Saleh, E. M. B. E. Naggar, A. E.-R. O. El-Shabrawy, and S. S. ElHawary, "HPLC-DAD-MS/MS profiling of phenolics from Securigera securidaca flowers and its anti-hyperglycemic and anti-hyperlipidemic activities," Revista Brasileira de Farmacognosia, vol. 25, no. 2, pp. 134-141, 2015.

[18] H. Kikuzaki, Y. Kawai, and N. Nakatani, "1, 1-Diphenyl-2picrylhydrazyl radical-scavenging active compounds from greater cardamom (Amomum subulatum Roxb.)," Journal of Nutritional Science and Vitaminology, vol. 47, no. 2, pp. 167-171, 2001.

[19] N. Fang, S. Yu, and R. L. Prior, "LC/MS/MS characterization of phenolic constituents in dried plums," Journal of Agricultural and Food Chemistry, vol. 50, no. 12, pp. 3579-3585, 2002.

[20] Y. Tine, F. Renucci, J. Costa, A. Wélé, and J. Paolini, “A method for LC-MS/MS profiling of coumarins in zanthoxylum zanthoxyloides (Lam.) B. Zepernich and timler extracts and essential oils," Molecules, vol. 22, no. 1, p. 174, 2017.

[21] W. Xu, G. Luo, F. Yu et al., "Characterization of anthocyanins in the hybrid progenies derived from Iris dichotoma and
I. domestica by HPLC-DAD-ESI/MS analysis," Phytochemistry, vol. 150, pp. 60-74, 2018.

[22] R. Stein-Chisholm, J. Beaulieu, C. Grimm, and S. Lloyd, "LCMS/MS and UPLC-UV evaluation of anthocyanins and anthocyanidins during rabbiteye blueberry juice processing," Beverages, vol. 3, no. 4, p. 56, 2017.

[23] I. M. Abu-Reidah, M. S. Ali-Shtayeh, R. M. Jamous, D. ArráezRomán, and A. Segura-Carretero, "HPLC-DAD-ESI-MS/MS screening of bioactive components from Rhus coriaria L. (Sumac) fruits," Food Chemistry, vol. 166, pp. 179-191, 2015.

[24] Y. Chen, H. Yu, H. Wu et al., "Characterization and quantification by LC-MS/MS of the chemical components of the heating products of the flavonoids extract in Pollen typhae for transformation rule exploration," Molecules, vol. 20, no. 10, pp. 18352-18366, 2015.

[25] A. Marquez, M. Dueñas, M. P. Serratosa, and J. Merida, "Identification by HPLC-MS of anthocyanin derivatives in raisins," Journal of Chemistry, vol. 20137 pages, Article ID 274893, 2012.

[26] M. Blunder, A. Orthaber, R. Bauer, F. Bucar, and O. Kunert, "Efficient identification of flavones, flavanones and their glycosides in routine analysis via off-line combination of sensitive NMR and HPLC experiments," Food Chemistry, vol. 218, pp. 600-609, 2017.

[27] S. G. Bobro, OI Tikhonov, and M. Y. Blazheyevskiy, "Quantitative determination of azelaic acid in "propolis" gel with the propolis phenolic hydrophobic drug for treating acne," Journal of Pharmacy and Pharmacology, vol. 3, no. 2, pp. 73-79, 2015.

[28] K. Schütz, M. Persike, R. Carle, and A. Schieber, "Characterization and quantification of anthocyanins in selected artichoke (Cynara scolymus L.) cultivars by HPLC-DAD-ESI-MS n," Analytical and Bioanalytical Chemistry, vol. 384, no. 7-8, pp. 1511-1517, 2006.

[29] J. Zheng, C. Ding, L. Wang et al., "Anthocyanins composition and antioxidant activity of wild Lycium ruthenicum Murr. from Qinghai-Tibet Plateau," Food Chemistry, vol. 126, no. 3, pp. 859-865, 2011.

[30] M. Kajdžanoska, V. Gjamovski, and M. Stefova, "HPLCDAD-ESI-MSn identification of phenolic compounds in cultivated strawberries from Macedonia," Macedonian Journal of Chemistry and Chemical Engineering, vol. 29, no. 2, pp. 181-194, 2010.

[31] A. Brito, J. Ramirez, C. Areche, B. Sepúlveda, and M. Simirgiotis, "HPLC-UV-MS profiles of phenolic compounds and antioxidant activity of fruits from three citrus species consumed in Northern Chile," Molecules, vol. 19, no. 11, pp. 17400-17421, 2014.

[32] D. Lopes-Lutz, J. Dettmann, C. Nimalaratne, and A. Schieber, "Characterization and quantification of polyphenols in Amazon grape (Pourouma cecropiifolia Martius)," Molecules, vol. 15, no. 12, pp. 8543-8552, 2010.

[33] F. Lopes-da-Silva, S. de Pascual-Teresa, J. Rivas-Gonzalo, and C. Santos-Buelga, "Identification of anthocyanin pigments in strawberry (cv Camarosa) by LC using DAD and ESI-MS detection," European Food Research and Technology, vol. 214, no. 3, pp. 248-253, 2002.

[34] Q. Chen, Y. Zhang, W. Zhang, and Z. Chen, "Identification and quantification of oleanolic acid and ursolic acid in Chinese herbs by liquid chromatography-ion trap mass spectrometry," Biomedical Chromatography, vol. 25, no. 12, pp. 1381-1388, 2011. 
[35] J. Sun, F. Liang, Y. Bin, P. Li, and C. Duan, "Screening noncolored phenolics in red wines using liquid chromatography/ ultraviolet and mass spectrometry/mass spectrometry libraries," Molecules, vol. 12, no. 3, pp. 679-693, 2007.

[36] M. M. Rahman, M. N. Alam, A. Ulla et al., "Cardamom powder supplementation prevents obesity, improves glucose intolerance, inflammation and oxidative stress in liver of high carbohydrate high fat diet induced obese rats," Lipids in Health and Disease, vol. 16, no. 1, p. 151, 2017.

[37] M. Lambert, E. Meudec, A. Verbaere et al., "A highthroughput UHPLC-QqQ-MS method for polyphenol profiling in rosé wines," Molecules, vol. 20, no. 5, pp. 7890-7914, 2015.

[38] G. J. Baxter, J. R. Lawrence, A. B. Graham, D. Wiles, and J. R. Paterson, "Identification and determination of salicylic acid and salicyluric acid in urine of people not taking salicylate drugs," Annals of Clinical Biochemistry, vol. 39, no. 1, pp. $50-55,2002$.

[39] M. Zhu, X. Zheng, Q. Shu et al., "Relationship between the composition of flavonoids and flower colors variation in tropical water lily (Nymphaea) cultivars," PloS One, vol. 7, no. 4, 2012.

[40] H. Abdul Rahman, N. Saari, F. Abas, A. Ismail, M. W. Mumtaz, and A. Abdul Hamid, "Anti-obesity and antioxidant activities of selected medicinal plants and phytochemical profiling of bioactive compounds," International Journal of Food Properties, vol. 20, no. 11, pp. 2616-2629, 2017.

[41] C. Roh and U. Jung, "Screening of crude plant extracts with anti-obesity activity," International Journal of Molecular Sciences, vol. 13, no. 2, pp. 1710-1719, 2012.

[42] A. Seyedan, M. A. Alshawsh, M. A. Alshagga, S. Koosha, and Z. Mohamed, "Medicinal plants and their inhibitory activities against pancreatic lipase: a review," Evidence-Based Complementary and Alternative Medicine, vol. 2015, Article ID 973143, 13 pages, 2015.

[43] K. W. Nderitu, N. S. Mwenda, N. J. Macharia, S. S. Barasa, and M. P. Ngugi, "Antiobesity activities of methanolic extracts of Amaranthus dubius, Cucurbita pepo, and Vigna unguiculata in progesterone-induced obese Mice," Evidence-Based Complementary and Alternative Medicine, vol. 2017, Article ID 4317321, 2017.

[44] H. M. AI-Yousef, W. H. Hassan, S. Abdelaziz, M. Amina, R. Adel, and M. A. El-Sayed, "UPLC-ESI-MS/MS profile and antioxidant, cytotoxic, antidiabetic, and antiobesity activities of the aqueous extracts of three different Hibiscus Species," Journal of Chemistry, vol. 2020, Article ID 6749176, 17 pages, 2020.

[45] H. Oliveira, A. Fernandes, N. Brás, N. Mateus, V. de Freitas, and I. Fernandes, "Anthocyanins as antidiabetic agents-in vitro and in silico approaches of preventive and therapeutic effects," Molecules, vol. 25, no. 17, p. 3813, 2020.

[46] K. Ashok Kumar, S. Ramachandra Setty, and L. Narsu, "Pharmacognostic and phytochemical investigations of stems of Hibiscus micranthus linn," Pharmacognosy Journal, vol. 2, no. 15, pp. 21-30, 2010.

[47] N. M. Wedick, A. Pan, A. Cassidy et al., "Dietary flavonoid intakes and risk of type 2 diabetes in US men and women," The American Journal of Clinical Nutrition, vol. 95, no. 4, pp. 925-933, 2012.

[48] E. Nicolle, F. Souard, P. Faure, and A. Boumendjel, "Flavonoids as promising lead compounds in type 2 diabetes mellitus: molecules of interest and structure-activity relationship," Current Medicinal Chemistry, vol. 18, no. 17, pp. 2661-2672, 2011.
[49] R. Vinayagam and B. Xu, "Antidiabetic properties of dietary flavonoids: a cellular mechanism review," Nutrition \& Metabolism, vol. 12, no. 1, pp. 1-20, 2015.

[50] J. B. Xiao and P. Högger, "Dietary polyphenols and type 2 diabetes: current insights and future perspectives," Current Medicinal Chemistry, vol. 22, no. 1, pp. 23-38, 2015.

[51] C. Proença, M. Freitas, D. Ribeiro et al., "Evaluation of a flavonoids library for inhibition of pancreatic $\alpha$-amylase towards a structure-activity relationship," Journal of Enzyme Inhibition and Medicinal Chemistry, vol. 34, no. 1, pp. 577588, 2019.

[52] J. M. D. Soares, A. E. B. Pereira Leal, J. C. Silva, J. R. G. S. Almeida, and H. P. de Oliveira, "Influence of flavonoids on mechanism of modulation of insulin secretion," Pharmacognosy Magazine, vol. 13, no. 52, pp. 639-646, 2017. 